\title{
Estimation of Packed Red Cells (PRC) Blood Stock Using Extended Kalman Filter as Management of Blood Transfusion at Blood Bank of PMI Surabaya
}

\author{
Abdul Muhith ${ }^{1}$, Teguh Herlambang ${ }^{2}$ \\ \{abdulmuhith@unusa.ac.id ${ }^{1}$, teguh@unusa.ac.id ${ }^{2}$ \}
}

\author{
Nursing Department, FKK - University of Nahdlatul Ulama Surabaya (UNUSA) ${ }^{1}$ \\ Information System Department - University of Nahdlatul Ulama Surabaya (UNUSA) ${ }^{2}$
}

\begin{abstract}
One of the main problems encountered in health service system in developing countries is shortage of enough safe blood supply to meet the demand for blood transfusion. The safety and availability of blood supply rely on the government's support and commitment to the improvement of the national blood transfusion services. Safe blood stock can change from time to time, while the demand for blood constantly increases. Such method is considered less effective due to the fact that very often the data of blood donor do not meet the requirements. So a software for blood supply estimation is required. This paper is study of blood demand estimation for blood type of Packed Red Cells (PRC) at blood bank of PMI Surabaya by using the method of Extended Kalman Filter (EKF). The simulation results show that Extended Kalman Filter method have high accuracy with an error of less than $3-4 \%$.
\end{abstract}

Keywords: Blood Transfusion, blood bank, blood stock.

\section{Introduction}

One of the main problems encountered in health service system in developing countries is shortage of enough safe blood supply to meet the demand for blood transfusion. The safety and availability of blood supply rely on the government's support and commitment to the improvement of the national blood transfusion services through an organisation run by the government or the appointed non profit institution such as PMI or voluntary blood donor organization. Safe blood stock can change from time to time, while the demand for blood constantly increases. The method used in the condition of less blood supply is by contacting several people randomly to have blood donor to meet the standard stock of blood to be processed into safe blood ready for distribution to those who need it. Such method is considered less effective due to the fact that very often the data of blood donor do not meet the requirements. So a software for blood supply estimation is required [1].

In this paper, the estimation of PRC blood demand is limited only to PMI Surabaya City. Estimates are made because a problem can sometimes be solved using presvious information or data related to the problem [2], [3]. One estimation method is the Extended Kalman Filter (EKF) which functions to minimize covariance error estimation in correction step [3]-[5]. The development of the Kalman Filter method is the Extended Kalman Filter (EKF) which is applied in. In this paper, the EKF method was implemented to estimate the demand for PRC blood as a material for consideration of blood transfusion management at blood bank PMI Surabaya City. 


\section{Extended Kalman Filter (EKF)}

The algorithm Extended Kalman Filter (EKF) can be seen [6], [7]:

Table 1. Extended Kalman Filter Algorithm

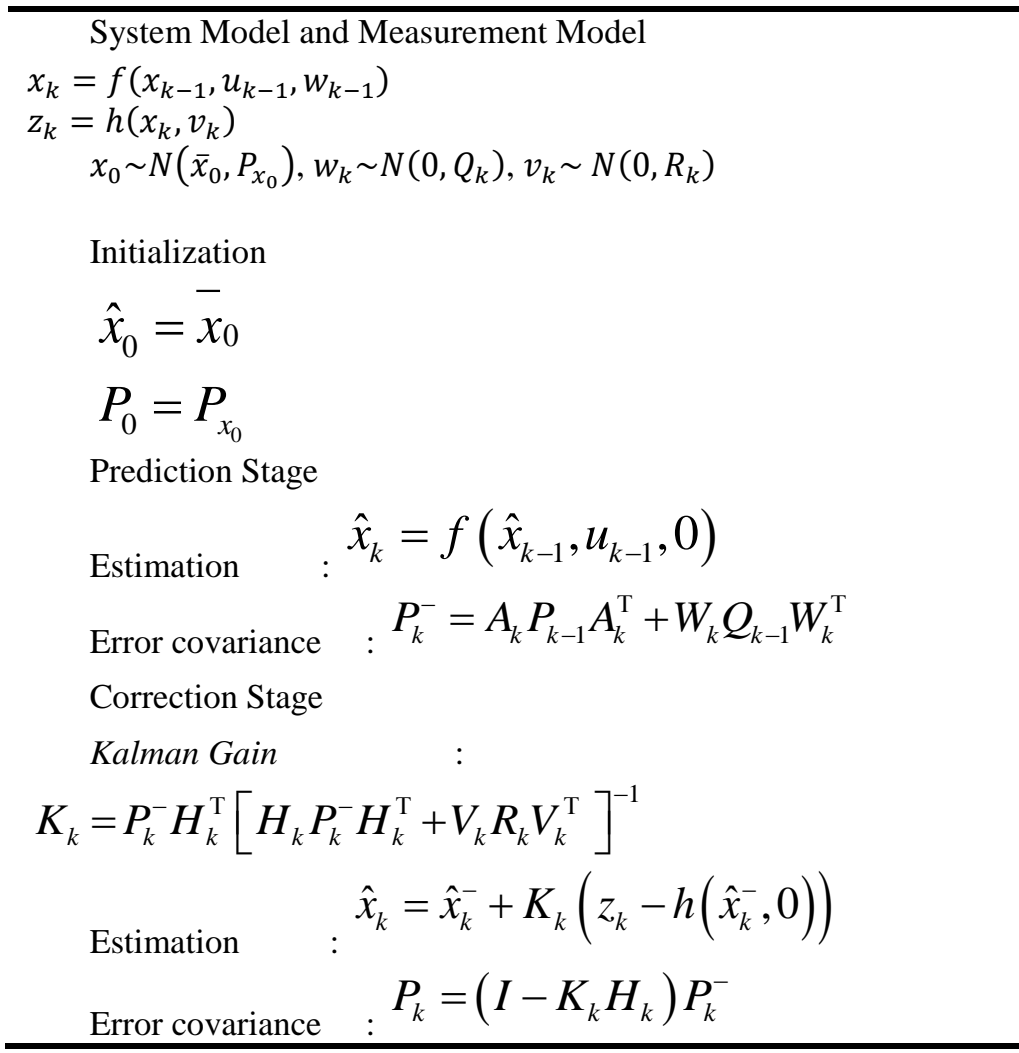

To approximate of estimation result accuracy by Extended Kalman Filter (EKF) algorithm, can be seen by computing Root Mean Square Error (RMSE) [8].

$$
\mathrm{RMSE}=\sqrt{\frac{\sum_{i}^{n}\left(X_{o b s, i}(k)-X_{\text {model }, i}(k)\right)^{2}}{n}}
$$

(1)

With

$$
\begin{array}{ll}
X_{\text {model }, i}(k) & =\text { model data } \\
X_{\text {obs }, i}(k) & =\text { observation data } \\
n & =\text { iteration }
\end{array}
$$

\section{Computational Result}

This simulation was implemented on PRC blood type data at PMI Surabaya city as follows: 
Table 2. Blood Data of PRC type [1]

\begin{tabular}{lcccccccccccc}
\hline & \multicolumn{10}{c}{ Data PRC } \\
\hline & Jan & Feb & Mar & Apr & May & Jun & Jul & Aug & Sep & Oct & Nov & Des \\
$\mathbf{2 0 1 4}$ & 4983 & 4431 & 4951 & 4190 & 4466 & 4229 & 4614 & 5050 & 4103 & 4392 & 4402 & 4469 \\
$\mathbf{2 0 1 5}$ & 5391 & 4296 & 4418 & 4212 & 4144 & 3762 & 3992 & 4274 & 4229 & 4353 & 4061 & 4351 \\
$\mathbf{2 0 1 6}$ & 4521 & 3886 & 3878 & 3925 & 3981 & 3698 & 3870 & 3851 & 3774 & 4023 & 3785 & 3763 \\
$\mathbf{2 0 1 7}$ & 3945 & 3499 & 3602 & 3526 & 3759 & 3535 & 4601 & 4090 & 3679 & 3814 & 3615 & 3599 \\
$\mathbf{2 0 1 8}$ & 3773 & 3956 & 3615 & 3599 & 4296 & 4418 & 4212 & 4144 & 3762 & 3992 & 4274 & 4229 \\
\hline
\end{tabular}

From the blood data of PRC type in Table 2, a mathematical function was obtained for the blood supply of PRC types using Mathematica software. The Mathematica software simulation resulted in a function as follows:

$f(x)=2397,5-2,561 x-0.461 x^{2}$

$f^{\prime}(x)=-2,561-0.922 x$

Because the system requires discretation, the PRC blood stock function model in equation (2) are discreted using the finite difference method. From equations (1), the modified PRC blood stock function model in (2) is obtained as follows:

$$
f_{k+1}=\left(-2,561-0.922 x_{k}\right) \Delta
$$

After the function was obtained, then it was computation simulated with the Matlab software. In this paper a simulation was implemented by applying the Extended Kalman Filter algorithm to the function of blood stock of PRC type. The simulation results were evaluated by comparing the real conditions in the field with the estimation results of EKF. This simulation used $\Delta t=0,1$ and 200, 300 and 400 iteration. Figure 1 is the estimation results using EKF methods using 100 iteration. Figure 2 is the simulation result of the EKF methods using 300 iteration. Figure 3 is a simulation of the EKF methods by 400 iteration.

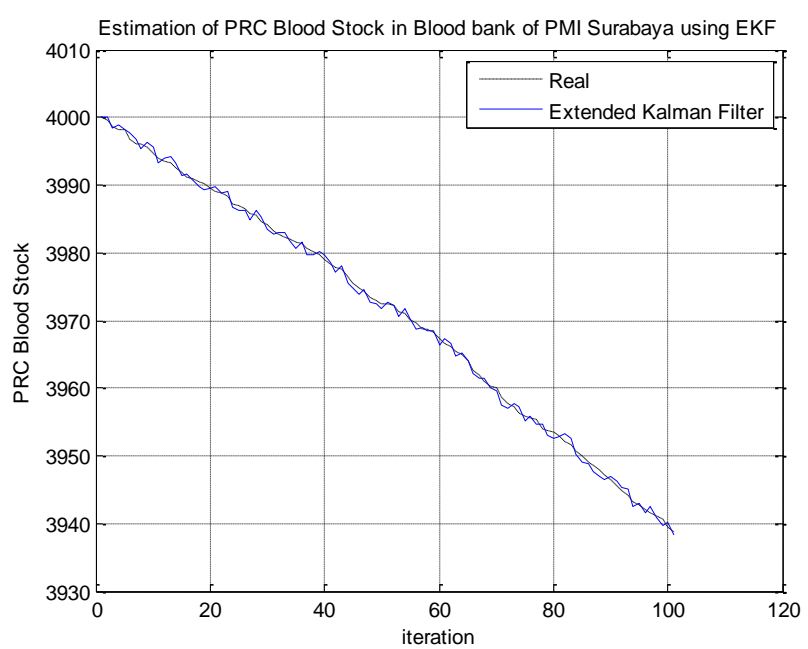

Fig. 1. Estimation of PRC blood stock using Extended Kalman Filter with 100 iteration 


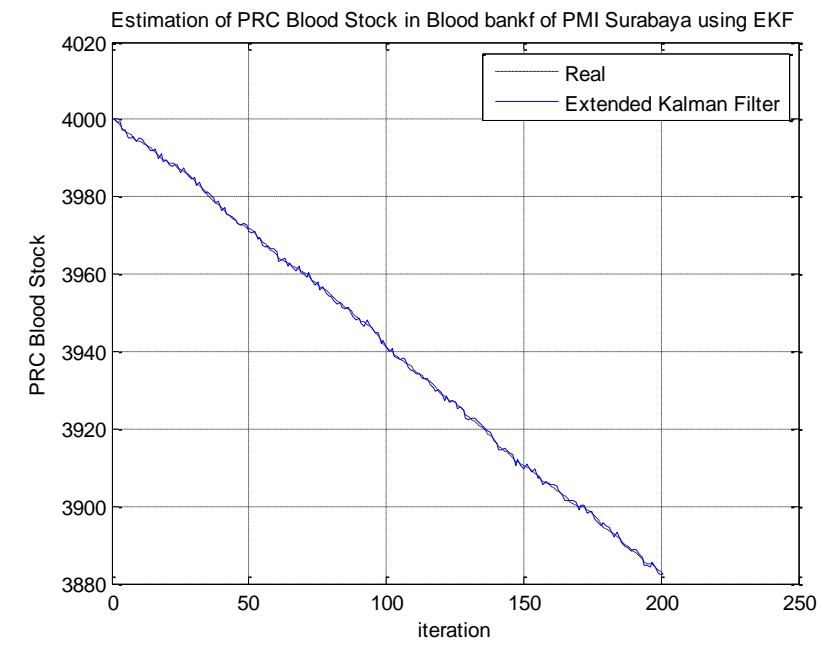

Fig. 2. Estimation of PRC blood stock using Extended Kalman Filter with 200 iteration

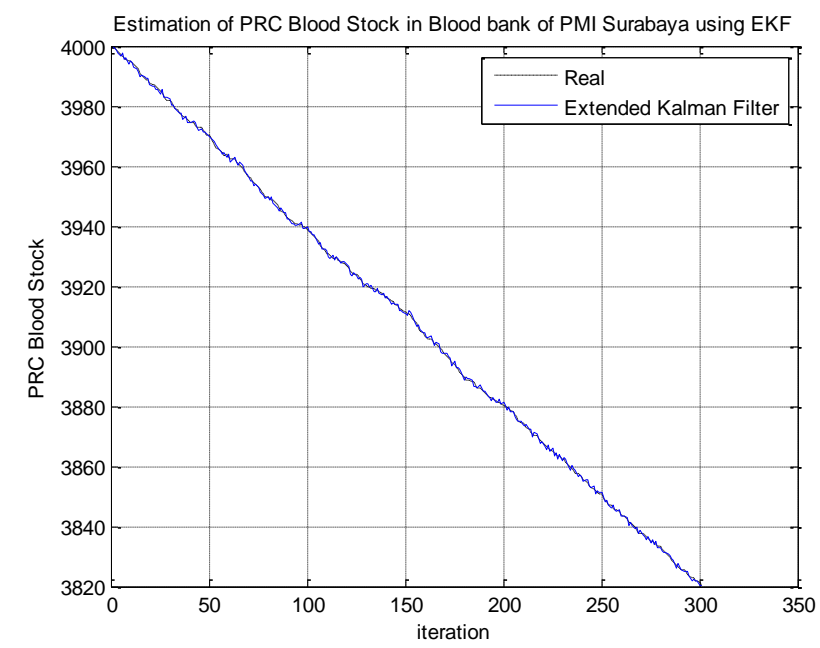

Fig. 3. Estimation of PRC blood stock using Extended Kalman Filter with 300 iteration

Figures 1, 2 and 3 indicate that the estimation results of PRC blood stock have high accuracy with errors of less than $1 \%$ as we can see in the real graphs. The accuracy of Extended Kalman Filter methods indicated no significant difference. In Figure 1 and Table 2, it shows that the EKF method having 300 iteration with RMSE of 0.083956 has higher accuracy $(97,3 \%)$ than that of 100 and 200 iteration with RMSE of 0.094883 and 0.089888 , but the difference is not much. Likewise, in Figures 2 and 3 with 200 and 300 iteration. In conclusion, EKF method can be effectively used as a method for estimating either PRC blood stock or other blood types. 
Table 2. Comparison of the RMSE values by the Extended Kalman Filter based on 100, 200 and 300 iteration

\begin{tabular}{ccccccc}
\hline & \multicolumn{2}{c}{ 100 Iteration } & \multicolumn{2}{c}{ 200 Iteration } & \multicolumn{2}{c}{ 300 Iteration } \\
& RMSE & Accuracy & RMSE & Accuracy & RMSE & Accuracy \\
\hline RMSE & 0.094883 & $96,2 \%$ & 0.089888 & $96,8 \%$ & 0.083956 & $97,3 \%$ \\
Simulation Time & \multicolumn{2}{c}{$5,897 \mathrm{~s}$} & \multicolumn{2}{c}{$8,127 \mathrm{~s}$} & \multicolumn{2}{c}{$9,856 \mathrm{~s}$} \\
& \multicolumn{2}{c}{} & \multicolumn{3}{c}{} \\
\hline
\end{tabular}

In Table 2, it appears that the EKF with 300 iteration method has higher accuracy than the EKF. even though the simulation time took longer time due to the number of iteration, making it more accurate in estimating. In general, the methods of EKF can be applied as a method to estimate or predict PRC blood stock with high accuracy. The simulation results above, indicate that EKF method can also be effectively used to estimate othertype of blood stock, then it can be support the work of PMI Surabaya's blood transfusion management in particular and blood bank of PMI in all cities in Indonesia in general.

\section{Conclusion}

Based on the results of the simulation analysis, the conclusion can be drawn be EKF method can be effectively applied as a method to estimate PRC blood stock with excellent accuracy and errors of less than $3 \%-4 \%$, and this method can also be utilized to estimate othertype of blood stock, so it can support the work of PMI Surabaya's blood transfusion management in particular and blood bank of PMI in all cities in Indonesia in general.

\section{References}

[1] W. H. Shanty, Firdaus, and T. Herlambang, "Prediction of Availability of Packed Red Cells (PRC) at PMI Surabaya City Using Ensemble Kalman Filter as Management of Blood Transfusion Management," in Journal of Physics: Conference Series, 2019.

[2] T. Herlambang, "Design of a navigation and guidance system of missile with trajectory estimation using ensemble Kalman Filter square root (EnKF-SR)," in Proceedings of the 2017 4th International Conference on Computer Applications and Information Processing Technology, CAIPT 2017, 2018.

[3] D. F. Karya, P. Katias, and T. Herlambang, "Stock price estimation using ensemble Kalman Filter square root method," in Journal of Physics: Conference Series, 2018.

[4] P. Katias, D. F. Karya, T. Herlambang, and H. Khusnah, "Ensemble kalman filter for crude oil price estimation," in Journal of Physics: Conference Series, 2019.

[5] D. Higdon et al., "Computer model calibration using the ensemble kalman filter," in Technometrics, 2013.

[6] T. Herlambang, Z. Mufarrikoh, D. F. Karya, and D. Rahmalia, "Estimation of water level and steam temperature using ensemble Kalman filter square root (EnKF-SR)," in Journal of Physics: Conference Series, 2018.

[7] P. T. Minh, B. T. Tuyet, T. T. T. Thao, and L. T. T. Hang, "Application of ensemble Kalman filter in WRF model to forecast rainfall on monsoon onset period in South Vietnam," VIETNAM J. EARTH Sci., 2018.

[8] T. Herlambang, E. B. Djatmiko, and H. Nurhadi, "Navigation and guidance control 
system of AUV with trajectory estimation of linear modelling," in ICAMIMIA 2015 International Conference on Advanced Mechatronics, Intelligent Manufacture, and Industrial Automation, Proceeding - In conjunction with Industrial Mechatronics and Automation Exhibition, IMAE, 2016. 